\section{Confirming anaphylaxis postmortem using serodiagnostic tests}

\author{
Pieter Meyer (1) 1,2
}

The difficulty of diagnosing anaphylaxis postmortem has remained a challenge during an autopsy investigation. The main challenges as summarised by Da Broi and Moreschi are:

1. Most cases occur outside the medical environment and are seldom witnessed, which means a lack of vital supportive information or medical history.

2. The lack or absence of internal and external signs (macroscopic and microscopic) of anaphylaxis at autopsy.

3. Biological fluids may be unavailable and chemical composition of analytes may be modified due to cytolytic or thanatological processes.

4. Biomarkers indicative of anaphylaxis are marred by a myriad of complications and remain mostly unreliable in forensic medicine.

5. Forensic experience, or the lack thereof, especially concerning the immunopathology of anaphylaxis also can curtail the diagnosis.

The main immunological biomarkers most commonly used in diagnosing allergy related anaphylaxis are mast cell tryptase (MCT), total IgE and allergen-specific IgE (sIgE) levels and have been used with some success in forensic pathology. However, the utility of these markers has been questioned due to varied cut-off values for positivity postmortem as both MCT and IgE have been shown to increase with prolonged postmortem intervals. ${ }^{2}$ During an anaphylactic episode circulatory MCT levels are elevated after $15-30 \mathrm{~min}$ post mast cell degranulation, peak at 2 hours

${ }^{1}$ Immunology, Faculty of Health Sciences, University of
Pretoria, Pretoria, South Africa
${ }^{2}$ Immunology, Tshwane Academic Division, National
Health Laboratory Service, Johannesburg, South Africa

Correspondence to Professor Pieter Meyer,

Immunology, University of Pretoria, Pretoria 0082,

South Africa; pieter.meyer@up.ac.za and return to normal levels after 3 days. Postmortem, MCT increases are due to several factors such as trauma an ensuing anaphylaxis, as well as the postmortem setting per se. These issues further exacerbate the interpretation of MCT levels determined during the autopsy. ${ }^{3-5}$ A recent review of MCT values in the postmortem setting has comprehensively established a positive value of $\geq 53.8 \mu \mathrm{g} / \mathrm{L}$ from femoral blood as indicative of anaphylaxis. As such, MCT levels above the indicated cutoff should be considered as an indicative test in assisting the diagnosis of anaphylactic death irrespective of contributing factors. $^{4}$

Although the use of serum total IgE postmortem seems unaffected either by trauma or an increased postmortem interval, its relevance remains doubtful as the anaphylaxis may be non-IgE mediated together with the prevalence of raised total $\operatorname{IgE}$ levels in allergic people. ${ }^{6}$ However, total $\operatorname{IgE}$ and sIgE from femoral and pericardial blood have been shown to be indicative of IgE levels at death and may support the diagnosing of anaphylaxis. ${ }^{7}$

Protein analysis of gastric content, vomitus and the prepared food as done in this case, to identify the causative agent is rare in postmortem investigations. The described preparation of these materials to prohibit further degradation of the samples and their analysis are informative and will be a useful inclusion in an autopsy protocol to assist in identifying the possible food source that may have triggered the anaphylaxis. As a reference, the Royal College of Pathologists has released anaphylaxis autopsy guidelines with little or no reference to this aspect in the autopsy investigation, ${ }^{8}$ which further strengthens the conclusions of this case study.

Handling editor Tahir S Pillay.
Contributors Concept, drafting and writing done by PM.

Funding The author has not declared a specific grant for this research from any funding agency in the public, commercial or not-for-profit sectors.

Competing interests None declared.

Patient consent for publication Not required.

Provenance and peer review Commissioned; internally peer reviewed.

(C) Author(s) (or their employer(s)) 2020. No commercial re-use. See rights and permissions. Published by BMJ.

D Check for updates

To cite Meyer P. J Clin Pathol 2020;73:781.

Received 27 August 2020

Accepted 16 September 2020

Published Online First 15 October 2020

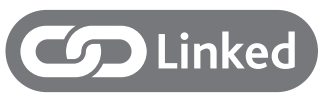

- http://dx.doi.org/10.1136/jclinpath-2020-206689

J Clin Pathol 2020;73:781.

doi:10.1136/jclinpath-2020-207056

ORCID iD

Pieter Meyer http://orcid.org/0000-0002-7318-1055

\section{REFERENCES}

1 Da Broi U, Moreschi C. Post-Mortem diagnosis of anaphylaxis: a difficult task in forensic medicine. Forensic Sci Int 2011;204:1-5.

2 Byard RW. Anaphylaxis at autopsy. Forensic Sci Med Pathol 2017;13:269-71.

3 Busardò FP, Marinelli E, Zaami S. Is the diagnosis of anaphylaxis reliable in forensics? the role of $\beta$-tryptase and its correct interpretation. Leg Med 2016;23:86-8.

4 Tse R, Wong CX, Kesha K, et al. Post mortem tryptase cut-off level for anaphylactic death. Forensic Sci Int 2018;284:5-8.

5 Garland J, Ondruschka B, Da Broi U, et al. Post mortem tryptase: a review of literature on its use, sampling and interpretation in the investigation of fatal anaphylaxis. Forensic Sci Int 2020;314:110415.

6 Tran L, Palmiere C. Postmortem serum levels of total IgE. Int J Legal Med 2016;130:1567-73.

7 Tran L, Astengo B, Palmiere C. Determination of specific $\lg$ E in pericardial and cerebrospinal fluids in forensic casework. Forensic Sci Int 2016;267:204-9.

8 Osborne M, Du Paroc J, Chambers D, et al. G170 autopsy for suspected acute anaphalaxis for consultation: the Royal College of pathologists, 2018. Available: https://www.rcpath.org/uploads/assets/ 47841b6b-891f-450a-b968889ff3e0a7d1/G170DRAFT-Guidelines-on-autopsy-practice-autopsy-forsuspected-acute-anaphalaxis-For-Consultation.pdf [Accessed 10 Aug 2020]. 